\title{
Microstructure response of cryogenically-rolled Cu-30Zn brass to electric-current pulsing
}

\author{
T. Konkova ${ }^{1,2}$, I. Valeev ${ }^{1}$, S. Mironov ${ }^{1,3^{*}}$, A. Korznikov ${ }^{1,4}$, G. Korznikova ${ }^{1}$ \\ M.M. Myshlyaev ${ }^{5,6}$, and S.L. Semiatin ${ }^{7}$ \\ 1 Institute for Metals Superplasticity Problems, Russian Academy of Science, 39 Khalturin Str., \\ Ufa, 450001, Russia \\ ${ }^{2}$ Advanced Forming Research Centre, University of Strathclyde, 85 Inchinnan Drive, Inchinnan, \\ PA4 9LJ United Kingdom \\ ${ }^{3}$ Department of Materials Processing, Graduate School of Engineering, Tohoku University, 6-6- \\ 02 Aramaki-aza-Aoba, Sendai 980-8579, Japan \\ ${ }^{4}$ National Research Tomsk State University, 36 Lenina av., Tomsk 634050, Russia \\ ${ }^{5}$ Baikov Institute of Metallurgy and Material Science, Russian Academy of Science, 49 Lenin-av., \\ Moscow 119991, Russia \\ 6 Institute of Solid State Physics, Russian Academy of Sciences, 2 Academic Osypian Str., \\ Chernogolovka, Moscow oblast, 142432 Russia \\ 7 Air Force Research Laboratory, Materials and Manufacturing Directorate, AFRL/RXCM, Wright- \\ Patterson AFB, OH 45433-7817, USA \\ The effect of transient electric-current pulses (ECP) on the evolution of \\ microstructure and texture of cryogenically-rolled Cu-30Zn brass was \\ determined. The pulsing was shown to lead to recrystallization followed by grain \\ growth. The mean grain size in the recrystallized material was $0.5 \mu \mathrm{m}$, thus \\ indicating that cryogenic rolling coupled with ECP is suitable for the production of \\ an ultrafine-grain microstructure in Cu-30Zn brass. The differences in the \\ recrystallization texture in pulsed versus statically-annealed conditions suggested \\ a distinct recrystallization mechanism during ECP.
}

Keywords: Cu-30Zn brass; Electric-current pulses; Cryogenic deformation; Electron backscatter diffraction; Grain structure; Texture

\section{Introduction}

Large deformation at cryogenic temperatures is sometimes considered as a promising and cost-effective method for the production of bulk fine-grain materials [e.g. 1-14]. The low deformation temperatures are believed to suppress dynamic recovery and stimulate mechanical twinning, thereby enhancing grainrefinement. Such an approach may reduce the level of stain required to achieve an ultrafine microstructure and thus enable the use of industrial working processes to produce ultrafine-grain materials.

For Cu-30Zn brass, cryogenic rolling coupled with subsequent recrystallization annealing was previously shown to be a simple and effective approach for producing an ultrafine microstructure $[15,16]$. As an extension of the previous research, the present effort was undertaken to determine the specific effect of electric-current pulses (ECP) of very short duration on the microstructure developed in this material.

\footnotetext{
* Corresponding author; E-mail address: smironov@material.tohoku.ac.jp, Tel: +81-22-795-7353,

Fax: +81-22-795-7352
} 
ECP treatment of cold worked commercially-purity copper has recently attracted significant interest [17-23]. In contrast, a review of the technical literature reveals only a single investigation of the influence of ECP on the microstructure developed in cold-rolled Cu-30Zn brass [24]. Here it was found that pulsing led to recrystallization, and the recrystallized grain size was smaller than that after static annealing. The grain-refinement effect during ECP was attributed to a high nucleation rate during recrystallization, associated with higher-than-normal peak temperatures, as well as to an increase in the mobility of dislocations in the presence of the electric current, i.e., the phenomenon sometimes referred to as "electron wind". Despite this previous research, many important aspects of microstructural response of deformed $\mathrm{Cu}-30 \mathrm{Zn}$ brass to ECP as well as the potential of this approach for producing an ultrafine microstructure are not clear. Hence, in this work, the electron back-scatter diffraction (EBSD) technique was applied to characterize microstructure evolution in detail and thereby provide deeper insight into the mechanisms of recrystallization and grain growth.

\section{Material and Experimental Procedures}

The program material comprised $\mathrm{Cu}-30 \mathrm{Zn}$ with a measured composition (in wt.\%) of $29.5 \mathrm{Zn}, 0.5 \mathrm{~Pb}$, balance $\mathrm{Cu}$ and traces of some other elements. The material was produced by ingot casting followed by $10 \%$ cold rolling and a subsequent $30-\mathrm{min}$ anneal at $800^{\circ} \mathrm{C}$. Sections of this material were then cryogenically rolled to 90 -pct. overall thickness reduction (true strain $=-2.3$ ) using multiple passes of $\sim 10$ pct. each. In order to provide cryogenic-deformation conditions, the rolling perform and work rolls were soaked in liquid nitrogen prior to each pass and held for 20 minutes; immediately after each pass, the workpiece was re-inserted into liquid nitrogen. The typical flat-rolling convention was adopted in this work; i.e., the rolling, long-transverse, and thickness/normal directions were denoted as RD, TD, and ND, respectively. The details of the cryo-rolling process are described elsewhere [13, 14].

ECP was performed under ambient conditions by discharge of a highvoltage capacitor bank through the cryo-rolled specimens ${ }^{\dagger}$. The waveform of the ECP was measured using a Rogowski coil [25] and C8-17 dual-trace storage oscilloscope and found to consist of a damped oscillation. Due to the relatively small specimen thickness, the skin effect was assumed to be negligible. Further details of the ECP treatment are described elsewhere [26].

The energy released during ECP was quantified by the integral current density, $\mathrm{K}_{\mathrm{j}}[25]$ :

$$
K_{j}=\int_{0}^{\tau} j^{2} \partial \tau=\frac{k^{2}}{S^{2}} \cdot \frac{A_{1}^{2}}{A_{2}} \cdot \frac{\tau}{4 \ln \left(\frac{A_{1}}{A_{3}}\right)} ;
$$

in which $j$ denotes the current density, $\tau$ is pulse duration, $k$ is the coefficient of the Rogowski coil ( $k=44 \mathrm{kA} / \mathrm{V}$ ), $S$ is the cross-sectional area of the pulsed specimen, and $A_{1}, A_{2}$ and $A_{3}$ are the first, second, and third amplitudes of the

\footnotetext{
† The specimen's layout during ECP is shown in Supplementary figure S1.
} 
damped current, respectively. The pulse duration was $140 \mu$ s in all cases. To establish the effect of ECP energy on structural response, the integral current density was varied from $K_{j}=1.34 \times 10^{4} \mathrm{~A}^{2} \mathrm{smm}^{-4}$ to $K_{j}=2.58 \times 10^{4} \mathrm{~A}^{2} \mathrm{smm}^{-4}$.

For comparison purposes, several cryo-rolled specimens were also furnace annealed under different temperature/time conditions. The details of such static heat-treatments are described elsewhere [15].

Microstructure observations and texture measurements were performed via EBSD. For this purpose, samples were prepared using conventional metallographic techniques followed by long-term $(24 \mathrm{~h})$ vibratory polishing with a colloidal-silica suspension. EBSD analysis was conducted using a Hitachi S4300SE field-emission-gun, scanning-electron microscope (FEG-SEM) equipped with a TSL EDAX OIM ${ }^{\mathrm{TM}}$ EBSD system. To determine the microstructure at various length scales, EBSD maps were acquired from each sample using different scan-step sizes ranging from 0.05 to $2 \mu \mathrm{m}$. To improve the reliability of the EBSD data, small grains comprising three or fewer pixels were automatically removed from the maps using the grain-dilation option in the TSL software. Furthermore, to eliminate spurious boundaries caused by orientation noise, a lower limit boundary-misorientation cutoff of $2^{\circ}$ was used. A $15^{\circ}$ criterion was employed to differentiate low-angle boundaries (LABs) and high-angle boundaries (HABs). Grains were defined as crystallites bordered by a continuous HAB perimeter.

The variation of chemical composition within the material was examined using an energy-dispersive X-ray spectroscopy (EDX) system installed in a Philips XL-30 FEG-SEM. To obtain a broader view of microstructural changes, Vickers microhardness profiles were also measured across the ECP-processed zone of each sample using a load of $100 \mathrm{~g}$ for $10 \mathrm{~s}$.

\section{Results and Discussion}

\subsection{Joule heating}

ECP is well accepted to lead to material (Joule) heating. However, due to the very short duration of the current pulse $\left(\sim 10^{-4} \mathrm{~s}\right)$, direct measurement of the temperature transients is essentially impossible. Thus, the temperature rise is usually estimated theoretically, e.g., from the following equation [25]:

$$
\frac{K_{j}}{\mu}=\int_{T_{0}}^{T_{K}} \rho c d T
$$

Here, $\mu$ denotes electrical conductivity; $T_{0}$ is room temperature; $T_{K}$ is the peak temperature developed in the specimen; and $\rho$ and $c$ are its density and specific heat, respectively. The temperature dependence of $\mu, \rho$, and $c$ are given in Supplementary Fig. S2. Using these values of the material coefficients, the relationship between the integral current density and the calculated peak temperature was determined (Fig. 1a). In the present work, the predicted temperature varied from $\sim 270^{\circ} \mathrm{C}\left(0.44 \mathrm{Tm}\right.$, in which $\mathrm{T}_{\mathrm{m}}$ denotes the melting point) at $\mathrm{K}_{\mathrm{j}}=1.29 \times 10^{4} \mathrm{~A}^{2} \mathrm{smm}^{-4}$ to $\sim 710^{\circ} \mathrm{C}(0.80 \mathrm{Tm})$ at $\mathrm{K}_{\mathrm{j}}=2.58 \times 10^{4} \mathrm{~A}^{2} \mathrm{smm}^{-4}$ (Fig. 1a). It should be noted, however, that the real temperature distribution in each 
pulsed sample was likely inhomogeneous, as shown in [23]. Hence, the calculated temperature should be considered as an approximate spatial average.

The rapid and localized heating also tends to give rise to heterogeneous thermal expansion and thus the development of a thermal stress. Quantification of such effects is difficult, but the approximate magnitude of the peak stress $\sigma_{\max }$ can be estimated from the following relation for a fully-constrained sample [28]:

$$
\sigma_{\text {max }} \approx E \alpha \Delta T
$$

Here, $E$ is Young's modulus $(11,200 \mathrm{MPa}$ at ambient temperature), $\alpha$ is the thermal expansion coefficient $\left(18.8 \times 10^{-6} \mathrm{C}^{-1}\right)$, and $\Delta T$ is the temperature rise. Using Equation (3), the maximum thermal stress was predicted to increase with temperature (i.e., integral current density) from $\sim 55 \mathrm{MPa}$ to $\sim 150 \mathrm{MPa}$ (Fig. $1 \mathrm{~b}$ ). These magnitudes are comparable to the yield strength of $\mathrm{Cu}-30 \mathrm{Zn}$ brass at ambient temperature $(75-450 \mathrm{MPa}$ [29]) and thus may give rise to plastic deformation during ECP processing. Indeed, cracking was observed in the specimens pulsed at $\mathrm{K}_{\mathrm{j}} \geq 2.1 \times 10^{4} \mathrm{~A}^{2} \mathrm{~s} \mathrm{~mm}^{-4}$, and the sample treated at $\mathrm{K}_{\mathrm{j}}=$ $2.58 \times 10^{4} \mathrm{~A}^{2} \mathrm{~s} \mathrm{~mm} \mathrm{~mm}^{-4}$ was totally fractured. The possible effect of the thermallyinduced stresses on microstructure evolution is discussed in Section 3.3.

\subsection{Dezincification}

During annealing of $\mathrm{Cu}-30 \mathrm{Zn}$ brass at relatively high temperatures, vaporization of $\mathrm{Zn}$ from the material (so-called dezincification) is known to occur [30]; this process is believed to become especially pronounced at $\sim 900^{\circ} \mathrm{C}$ [31]. Furthermore, if the pulsing were to give rise to the "electron-wind" effect, dezincification might be enhanced. To examine this possibility, the concentration of zinc at the free surface of the sheets was measured as a function of integral current density (Fig. 2). It was found that the zinc content was reduced only slightly, if at all, and did not depend systematically on integral current density/peak temperature.

\subsection{Grain structure}

Selected portions of grain-boundary EBSD maps showing the characteristic grain structures which were developed during cryo-rolling or subsequent pulsing at different integral current densities are shown in Fig. 3. For comparison purposes, the microstructures of several statically-annealed specimens are given in Fig. 4. In these maps, LABs, HABs, and $\Sigma 3$ twin boundaries (within a $5^{\circ}$ tolerance) are depicted by red ${ }^{\ddagger}$, black, and gray lines, respectively. Misorientation and grain-size measurements are summarized in Figs. 5 and 6 , respectively.

The microstructure of the as-cryo-rolled sample (Fig. 3a) was markedly inhomogeneous and could be described in terms of remnants of coarse original grains with poorly-developed substructure and ultrafine-grain domains. The latter regions consisted of shear bands, mechanical twins, and a dense LAB substructure. The mean grain size in the ultrafine-grain areas was $\sim 0.2 \mu \mathrm{m}$. As

\footnotetext{
$\$$ The reader is referred to on-line version of the paper to view the figures in color.
} 
shown in previous papers $[13,14]$, the formation of this microstructure was related to the very heterogeneous character of microstructure evolution during cryogenic rolling.

Electric pulsing at $\mathrm{K}_{\mathrm{j}}=1.29 \times 10^{4} \mathrm{~A}^{2} \mathrm{smm}^{-4}$ led to significant microstructural changes (Fig. $3 b$ ). The principal features comprised a number of nearly-equiaxed LAB-free grains within the original heavily-deformed matrix, i.e., the microstructure had become essentially bimodal. The very large difference between the microstructural constituents suggested that the material had undergone the initial stages of recrystallization. In addition, the recrystallized grains often contained annealing twins as well. These observations suggested that microstructure development during pulsing presumably involved nucleation and growth of recrystallization nuclei, i.e. discontinuous recrystallization. The growth of the recrystallized grains partially eliminated LABs and increased the proportion of $\Sigma 3$ (twin) boundaries (Fig. 5a). Remarkably, the predicted peak temperature during ECP of this sample was $\sim 270^{\circ} \mathrm{C}(0.44 \mathrm{Tm})$ (Fig. 1a), which is lower than the typical recrystallization temperature for heavily-cold-worked $\mathrm{Cu}$ $30 \mathrm{Zn}$ brass $\left(\sim 280^{\circ} \mathrm{C}[32]\right)$.

An increase of the integral current density to $\mathrm{K}_{\mathrm{j}}=1.34 \times 10^{4} \mathrm{~A}^{2} \mathrm{smm}^{-4}$ resulted in a nearly-completely-recrystallized grain structure (Fig. 3c). This reduced the $L A B$ fraction to $\sim 10$ pct., and increased the fraction of $\Sigma 3$ annealingtwin boundaries to $\sim 50$ pct. (Fig. 5a). However, the overall microstructure was somewhat inhomogeneous, comprising both relatively-small and large grains (Figs. 3c). This non-uniformity likely resulted from differences in the recrystallization kinetics for the fine- and coarse-grain constituents of the cryorolled material seen in Fig. 3a. Nevertheless, the mean grain size (including twin boundaries) was still rather fine, i.e., $\sim 0.5 \mu \mathrm{m}$ (Fig. 6a), thus lying within the ultrafine-grain regime. Hence, it has been demonstrated that cryogenic rolling coupled with ECP at a relatively low current density can indeed produce an ultrafine-grain microstructure.

It is important to note that a recrystallized microstructure was developed at a predicted peak temperature of only $\sim 285^{\circ} \mathrm{C}(0.45 \mathrm{Tm})\left(\right.$ Fig. 1a) with $\mathrm{K}_{\mathrm{j}}=1.34 \mathrm{x}$ $10^{4} \mathrm{~A}^{2} \mathrm{smm}^{-4}$. By contrast, static annealing of the cryo-rolled material at $300^{\circ} \mathrm{C}$ for $1 \mathrm{~h}$ produced only a partially-recrystallized microstructure (Fig. 4a). To complete the recrystallization process during static heat treatment, annealing at $400^{\circ} \mathrm{C}$ $(0.55 \mathrm{Tm})$ was required (Fig. 4b). Despite the significant temperature difference, the recrystallized materials in both the pulsed and statically-annealed conditions showed broad similarity in microstructure morphology (e.g., Fig. 3c vs Fig. 4b), misorientation distribution, and grain-size distribution (Figs. $5 b$ \& $6 b$, respectively).

Further increases in the current density led to microstructure coarsening which, however, saturated at $\mathrm{K}_{\mathrm{j}} \sim 1.6 \times 10^{4} \mathrm{~A}^{2} \mathrm{smm}^{-4}$ (Fig. 6a). Simultaneously, the twin boundary fraction decreased to $\sim 40$ pct. (Fig. 5a). The microstructures which evolved at the highest integral current densities were dominated by lowaspect-ratio grains containing a significant proportion of annealing twins but typically almost no LABs (Fig. 3d). In terms of morphology and misorientation/ grain-size distributions, the microstructures were somewhat similar to that 
produced during static annealing at $500^{\circ} \mathrm{C}(0.63 \mathrm{Tm})$ for $1 \mathrm{~h}$ (Figs. $\left.4 \mathrm{c}, 5 \mathrm{c}, 6 \mathrm{~b}\right)$. It is likely therefore that final microstructure formation in these pulsed specimens was governed by grain growth, similar to that during static annealing. It should be emphasized that the peak temperature for the higher integral current densities was predicted to increase continuously from $\sim 400^{\circ} \mathrm{C}(0.55 \mathrm{Tm})$ to $710^{\circ} \mathrm{C}(0.80 \mathrm{Tm})$ (Fig. 1a). However, in view of the very short duration of the pulsing treatment $\left(\sim 10^{-4} \mathrm{~s}\right)$, the majority of the grain growth occurred presumably during the cooling stage of the ECP treatments, as has been suggested previously [23]. Nevertheless, the still relatively-short cooling time explains perhaps the observed insensitivity of grain growth to pulsing temperature (Fig. 6a).

It is also worth noting the microstructures produced during pulsing at high integral current densities contained isolated grains with poorly-developed LAB substructure (e.g., the region circled in Fig. 3d). This phenomenon may be related to large thermal stresses and concomitant plastic strain under these conditions (Fig. 1b) as discussed in Section 3.1.

\subsection{Texture}

To provide additional insight into the ECP process, texture evolution was quantified using orientation distribution functions (ODFs) (Fig. 7) derived from the EBSD maps. An ODF showing the ideal rolling textures typically developed in face-centered-cubic metals is also presented here (Fig. 7a). Moreover, ODFs of several statically-annealed samples are shown in Fig. 8.

The cryo-rolled material was characterized by a relatively-strong texture which could be described in terms of the superposition of two partial fibers: $\alpha$ $<110>/ / N D$ and $\gamma<111>/ / N D$; the $\alpha$ fiber was more pronounced than the $\gamma$ fiber (Fig. 7b). Within the $\alpha$-fiber, strong Brass $\{110\}<112>$ and Goss $\{110\}<100>$ components were noted, whereas the $\gamma$-fiber was dominated by the $Y$ $\{111\}<112>$ texture component (Fig. 7b). As shown in previous efforts [13, 14], the Brass and Goss orientations were mainly found in coarse-grain remnants, whereas the $\gamma$-fiber and $Y$ component originated from the ultrafine-grain domains of the cryo-rolled microstructure.

Partial recrystallization occurring during pulsing at $\mathrm{K}_{\mathrm{j}}=1.29 \times 10^{4} \mathrm{~A}^{2} \mathrm{smm}^{-4}$ significantly enlarged the orientation spread and thus weakened the strength of the overall texture (Fig. 7c). The intensities of the $\alpha$-fiber as well as the Brass and Goss components were reduced (Fig. 7c). Moreover, the $\gamma$-fiber and the $Y$ orientation disappeared almost completely (Fig. 7c); this perhaps provided evidence that recrystallization developed most rapidly in the shear-band regions.

The completion of the recrystallization process at $\mathrm{K}_{\mathrm{j}}=1.34 \times 10^{4} \mathrm{~A}^{2} \mathrm{smm}^{-4}$ produced a somewhat different texture (Fig. 7d) which, however, exhibited a number of similarities to the texture of statically-recrystallized material (Fig. 8a, Table 1). In both conditions, the textures were dominated by the Brass- $R$ $(79 ; 31 ; 33)$ orientation, but also contained a significant fraction of Brass $(35 ; 45 ; 0)$ and Goss $(0 ; 45 ; 0)$ components. These orientations were as expected in recrystallized materials with low stacking-fault energy, including $\mathrm{Cu}-30 \mathrm{Zn}$ brass [26]. However, the pulsed material also contained a relatively-large proportion of the $\mathrm{P}(70 ; 45 ; 0)$ texture component (Fig. $7 \mathrm{~d}$, Table 1). The difference between the 
textures of the statically-annealed (Fig. 8a) and pulsed (Fig. 7d) samples did suggest that the recrystallization mechanisms were not identical. Specifically, the development of $P$ texture during recrystallization of rolled face-centered metals has been sometimes attributed to the interaction between recrystallization and second-phase particles [33,34]. Indeed, the precipitation of secondary particles has been recently revealed during static annealing of cryogenically rolled $\mathrm{Cu}$ $30 \mathrm{Zn}$ brass [35]. Electric pulsing may enhance this process and thus affect the mechanism of recrystallization nucleation. This hypothesis requires experimental verification, however.

The textures developed at higher integral current densities were characterized by a superposition of a pronounced Brass- $R$ component and relatively strong $\alpha$ fiber (Fig. 7e), and thus were similar to that developed during static annealing (Fig. 8b). This similarity likely indicated the similarity of graingrowth mechanisms for these annealing conditions.

\subsection{Microstructure-strength relationship}

The benefit of the ECP on strength was quantified, at least approximately, by the microhardness traverses measured across the pulsed specimens; typical examples are shown in Fig. 9a. As expected, recrystallization and subsequent grain growth provided significant softening. Furthermore, the microhardness varied measurably in the processed zone, thus perhaps indicating an inhomogeneous temperature distribution during pulsing, as suggested in Section 3.1.

The mean microhardness in the central part of the pulsed samples decreased with integral current density (Fig. 9b). It reached a minimum for $\mathrm{K}_{\mathrm{j}} \geq$ $1.6 \times 10^{4} \mathrm{~A}^{2} \mathrm{smm}^{-4}$ (Fig. 9b). This finding agreed well with the observation of a corresponding plateau in grain size (Fig. 6a), as discussed in Section 3.3.

To evaluate the microstructure-strength relationship, the microhardness data were arranged as a Hall-Petch plot (Fig. 9c). The reasonably good agreement between the experimental data and this classical model indicated perhaps that the material strength was governed primarily by grain size, i.e., the thermal stress did not result in significant work-hardening, at least in the central part of the processed zone. It should be noted however, the applicability of the Hall-Petch fit in terms of microhardness data is somewhat approximate for two reasons. First, the imposed strain in hardness tests is relatively large $(\sim 0.05-$ $0.10)$. Hence the measured hardness values are averages of flow stress over a wide range of strain. Because the work-hardening rate and average flow stress may vary with grain size (due to complex slip and possibly deformation-twinning processes), the true yielding behavior is masked in hardness data. Second, the hardness values may also be influenced by texture differences in the various samples, as shown in Figs. 7c-e.

\section{Summary and Conclusions}

The effect of electric current pulses (ECP) on the evolution of microstructure and texture in cryogenically-rolled $\mathrm{Cu}-30 \mathrm{Zn}$ brass was established. To this end, the material was rolled to a $90 \%$ thickness reduction at liquid-nitrogen temperature and then pulsed at an integral current density $\mathrm{K}_{\mathrm{j}}$ 
ranging from $1.29 \times 10^{4} \mathrm{~A}^{2} \mathrm{smm}^{-4}$ to $2.58 \times 10^{4} \mathrm{~A}^{2} \mathrm{smm}^{-4}$. Grain structure and texture changes were quantified using an EBSD technique. The main conclusions from this work are as follows:

1) ECP results in recrystallization and grain growth. For the processing conditions investigated in the present work, the temperature rise induced by Joule heating has been estimated to range from $270^{\circ} \mathrm{C}(0.44 \mathrm{Tm})$ to $710^{\circ} \mathrm{C}$ $(0.80 \mathrm{Tm})$, the specific value depending on the integral current density. The maximum thermal stresses associated with inhomogeneous thermal expansion have been estimated to increase from $55 \mathrm{MPa}$ to $150 \mathrm{MPa}$.

2) Recrystallization textures in pulsed vs statically-annealed specimens are somewhat different. Specifically, the ECP material exhibits a relatively-high proportion of the $\mathrm{P}(0 ; 45 ; 0)$ orientation. Moreover, the estimated recrystallization temperature during pulsing $\left(\sim 285^{\circ} \mathrm{C}\right.$ or $\left.0.46 \mathrm{Tm}\right)$ is noticeably lower than that for static annealing $\left(400^{\circ} \mathrm{C}\right.$ or $\left.0.55 \mathrm{Tm}\right)$. These observations thus suggest a somewhat different recrystallization mechanism for the ECP process.

3) With optimal processing conditions, the mean grain size in the recrystallized condition is $\sim 0.5 \mu \mathrm{m}$. Therefore, cryogenic rolling coupled with ECP can be used to produce an ultrafine-grained structure in Cu-30Zn brass. However, the processing window is relatively narrow, i.e., from $\mathrm{K}_{\mathrm{j}}=1.34 \times 10^{4} \mathrm{~A}^{2} \mathrm{smm}^{-4}$ to $K_{j}=1.42 \times 10^{4} \mathrm{~A}^{2} \mathrm{smm}^{-4}$.

4) Further increases in integral current density above $\sim 1.4 \times 10^{4} \mathrm{~A}^{2} \mathrm{smm}^{-4}$ lead to rapid grain growth, which plateaus at $\mathrm{K}_{\mathrm{j}} \sim 1.6 \times 10^{4} \mathrm{~A}^{2} \mathrm{smm}^{-4}$. The microstructure and texture developed using such higher integral current densities are broadly similar to those produced during static annealing at $500^{\circ} \mathrm{C}$ for $1 \mathrm{~h}$. Considering the very short duration of ECP per se $\left(\sim 10^{-4} \mathrm{~s}\right)$, grain growth in these cases likely occurs predominantly during cooling of pulsed specimens to ambient temperature. The observed maximum in the final grain size during ECP may thus be attributed to limited cooling time.

5) Recrystallization and grain growth developed in ECP specimens lead to measurable softening. The dependence of microhardness on grain size can be described in terms of a Hall-Petch-like relation.

\section{Acknowledgements}

Financial support from the Russian Fund for Fundamental Research (project No. 14-02-97004) is gratefully acknowledged. The authors are grateful to $P$. Klassman for technical assistance during cryogenic rolling.

\section{References}

[1] Y. Estrin, N.V. Isaev, S.V. Lubenets, S.V. Malykhin, A.T. Pugachov, V.V. Pustovalov, E.N. Reshetnyak, V.S. Fomenko, S.E. Shumilin, M. Janecek, R.J. Hellmig, Effect of microstructure on plastic deformation of $\mathrm{Cu}$ at low homologous temperatures, Acta Mater.54 (2006) 5581-5590; doi:10.1016/i.actamat.2006.07.036

[2] Y.S. Li, N.R. Tao, K. Lu, Microstructural evolution and nanostructure formation in copper during dynamic plastic deformation at cryogenic temperatures, Acta Mater. 56 (2008) 230-241; doi:10.1016/j.actamat.2007.09.020 
[3] Y. Huang, P.B. Prangnell, The effect of cryogenic temperature and change in deformation mode on the limiting grain size in a severely deformed dilute aluminum alloy, Acta Mater. 56 (2008) 1619-1632; doi:10.1016/j.actamat.2007.12.017

[4] Y. Zhang, N.R. Tao, K. Lu, Mechanical properties and rolling behaviors of nano-grained copper with embedded nano-twin bundles, Acta Mater. 56 (2008) 2429-2440; doi:10.1016/i.actamat.2008.01.030

[5] K.P. Sushanta, R. Jayaganathan, A study of the mechanical properties of cryorolled Al-Mg-Si alloy, Mater. Sci. Eng. A480 (2008) 299-305; doi:10.1016/i.msea.2007.07.024

[6] V. Subramanya Sarma, K. Sivaprasad, D. Sturm, M. Heilmaier, Microstructure and mechanical properties of ultra fine grained $\mathrm{Cu}-\mathrm{Zn}$ and $\mathrm{Cu}-\mathrm{Al}$ alloys produced by cryorolling and annealing, Mater. Sci Eng. A489 (2008) 253-258; doi:10.1016/..msea.2007.12.016

[7] K.P. Sushanta, R. Jayaganathan, V. Chawla, Effect of cryorolling on microstructure of Al-MgSi alloy, Mater. Lett. 62 (2008) 2626-2629; doi:10.1016/..matlet.2008.01.003

[8] G.H. Xiao, N.R. Tao, K. Lu, Microstructures and mechanical properties of a Cu-Zn alloy subjected to cryogenic dynamic plastic deformation, Mater. Sci. Eng. A513-514 (2009) 13-21; doi:10.1016/..msea.2009.01.022

[9] T. Konkova, S. Mironov, A. Korznikov, S.L. Semiatin, Microstructural response of pure copper to cryogenic rolling, Acta Mater. 58 (2010) 5262-5273; doi:10.1016/j.actamat.2010.05.056

[10] J. Das, Evolution of nanostructure in $\alpha$-brass upon cryorolling, Mater. Sci. Eng. A530 (2011) 675-679; doi:10.1016/i.msea.2011.10.002

[10] S.V. Zherebtsov, G.S. Dyakonov, A.A. Salem, V.I. Sokolenko, G.A. Salishchev, S.L. Semiatin, Formation of nanostructures in commercial-purity titanium via cryorolling, Acta Mater. 61 (2013) 1167-1178; doi:10.1016/j.actamat.2012.10.026

[12] N.K. Kumar, B. Roy, J. Das, Effect of twin spacing, dislocation density, and crystallite size on the strength of nanostructured $\alpha$-brass, J. Alloys Comp. 618 (2015) 139-145; doi:10.1016/j.jallcom.2014.08.131

[13] T. Konkova, S. Mironov, A.V. Korznikov, G. Korznikova, M.M. Myshlyaev, S.L. Semiatin, Grain structure evolution during cryogenic rolling of alpha brass, J. Alloys Comp. 629 (2015) 140-147; doi:10.1016/i.jallcom.2014.12.241

[14] T. Konkova, S. Mironov, A.V. Korznikov, G. Korznikova, M.M. Myshlyaev, S.L. Semiatin, An EBSD investigation of cryogenically-rolled Cu-30\%Zn brass, Mater. Character. 101 (2015) 173179; doi:10.1016/j.matchar.2015.02.004

[15] T.N. Konkova, S.Yu. Mironov, A.V. Korznikov, M.M. Myshlyaev, S.L. Semiatin, Annealing behaviour of cryogenically-rolled copper, Mater. Sci. Eng. A585 (2013) 178-189; doi:10.1016/j.msea.2013.07.042

[16] T. Konkova, S. Mironov, A.V. Korznikov, G. Korznikova, M.M. Myshlyaev, S.L. Semiatin, A two-step approach for producing an ultrafine-grain structure in Cu-30Zn brass, Mater. Letter., 161 (2015) 1-4; doi:10.1016/i.matlet.2015.08.025

[17] R.F. Zhu, G.Y. Tang, S.Q. Shi, M.W. Fu, Microstructure evolution of copper strips with gradient temperature in electropulsing treatment, J. All. Comp. 581 (2013) 160-165; doi:10.1016/j.jallcom.2013.07.017

[18] R.F. Zhu, J.N. Liu, G.Y. Tang, S.Q. Shi, M.W. Fu, Properties, microstructure and texture evolution of cold rolled Cu strips under electropulsing treatment, J. All. Comp. 544 (2012) 203208; doi:10.1016/j.jallcom.2012.07.150

[19] Z. Xu, G. Tang, S. Tian, J. He, Research on the engineering application of multiple pulses treatment for recrystallization of fine copper wire, Mater. Sci. Eng. A 424 (2006) 300-306; doi:10.1016/j.msea.2006.03.012

[20] S.H. Xiao, J.D. Guo, S.D. Wu, G.H. He, S.X. Li, Recrystallization in fatigued copper single crystals under electropulsing, Scripta Mater. 46 (2002) 1-6; doi:10.1016/S1359-6462(01)01186-1 [21] X. Suhong, Z. Yizhou, G. Jingdong, W. Shiding, Y. Ge, L. Shouxin, H. Guanhu, Z. Benlian, The effect of high current pulsing on persistent slip bands in fatigued copper single crystals, Mater. Sci. Eng. A332 (2002) 351-355; doi:10.1016/S0921-5093(01)01822-6

[22] S.H. Xiao, J.D. Guo and S.X. Li, The effect of electropulsing on dislocation structures in [233] coplanar double-slip oriented fatigued copper single crystals, Phil. Mag. Letters, 82 (2002) 617622; doi:10.1080/0950083021000030397 
[23] T. Konkova, I. Valeev, S. Mironov, A.V. Korznikov, M.M. Myshlyaev, S.L. Semiatin, Effect of electric-current pulses on grain-structure evolution in cryogenically-rolled copper, J. Mater. Res. 29 (2014) 2727-2737; doi:10.1557/jmr.2014.299

[24] Y. Zhou, S. Xiao, J. Guo, Recrystallization microstructure in cold worked brass produced by electropulsing treatment, Mater. Letter.58 (2004) 1948-1951; doi:10.1016/..matlet.2003.11.035

[25] H. Knoepfel, Pulsed High Magnetic Fields, North-Holland Publishing Company, Amsterdam, 1970, 392p.

[26] I.Sh. Valeev, Z.G. Kamalov, Structure evolution in copper resulting from the effect of powerful current pulses, J. Mater. Eng. Perform. 12 (2003) 272-278; doi:10.1361/105994903770343114

[27] L.N. Larikov, Yu.F, Yurchenko, Structure and Properties of Metals and Alloys Handbook, Naukova Dumka, Kiev, 1985, 438 p. (in Russian)

[28] D.W. Tang, B.L. Zhou, H. Cao, G.H. He, Thermal stresses in thin films under transient laserpulse heating, J. Appl. Phys. 73 (1993) 3749-3752; doi: 10.1063/1.352907

[29] J.R. Davis, Copper and Copper Alloys, ASM Specialty Handbook, Materials Park, OH, USA, 2001, ISBN: 0-87170-726-8

[30] F.W. Giacobbe, Thermodynamic dezincification behavior of brass during annealing, J. Alloys Comp. 202 (1993) 243-250; doi:10.1016/0925-8388(93)90546-Y

[31] J.-M. Koo, H. Araki, S.-B. Jung, Effect of $\mathrm{Zn}$ addition on mechanical properties of brass hollow spheres, Mater. Sci. Eng. A483-484 (2008) 245-257; doi:10.1016/j.msea.2006.01.183

[32] F.J. Humphreys, M. Hatherly, Recrystallization and related phenomena, Elsevier, 2004, $574 p$.

[33] O. Engler, V. Randle, Introduction to Texture Analysis: macrotexture, microtexture, and orientation mapping, Second edition ed., CRC Press, Boca Raton, FL, 2009, 199p.

[34] S. Tangen , K. Sjolstad, T. Furu, E. Nes, Effect of concurrent precipitation on recrystallization and evolution of the P-texture component in a commercial Al-Mn alloy, Metall. Mater. Trans. A 41 (2010) 2970-2983; doi:10.1007/s11661-010-0265-8.

[35] T. Konkova, S. Mironov, A.V. Korznikov, G. Korznikova, M.M. Myshlyaev, S.L. Semiatin, Grain growth during annealing of cryogenically-rolled Cu-30Zn brass, submitted to J. All. Comp. 